Baas, C.I., Wiegers, T.A., Cock, T.P. de, Erwich, J.J.H.M., Spelten, E.R., Hutton, E.K. Experiencewith and amount of postpartum maternity care: comparing women who rated the care they received from the maternity care assistant as 'good' or 'less than good care'. Midwifery: 2017, 7 55(12), 128-236

\begin{tabular}{|l|l|}
\hline $\begin{array}{l}\text { Postprint } \\
\text { Version }\end{array}$ & 1.0 \\
\hline Journal website & https://linkinghub.elsevier.com/retrieve/pii/S0266-6138(17)30204-8 \\
\hline Pubmed link & $\underline{\text { https://www.ncbi.nlm.nih.gov/pubmed/29024880 }}$ \\
\hline DOI & $10.1016 /$ j.midw.2017.09.007 \\
\hline
\end{tabular}

This is a NIVEL certified Post Print, more info at http://www.nivel.eu

\title{
Experience with and amount of postpartum maternity care: Comparing women who rated the care they received from the maternity care assistant as 'good' or 'less than good care'
}

C.I.BAASRM, MSC, PHD CANDIDATE ${ }^{A}$ T.A.WIEGERSPHD(DR, SENIOR RESEARCHER ${ }^{\mathrm{B}}$ T.P.DE COCKPHD(RESEARCH ASSOCIATE) ${ }^{\mathrm{C} J . J . H . M . E R W I C H M D(P R O F E S S O R ~ O F ~}$ OBSTETRICS) ${ }^{\mathrm{D}}$ E.R.SPELTENPHD(DR, SENIOR LECTURER) ${ }^{\mathrm{E}}$ E.K.HUTTONRM, PHD(PROFESSOR, ASSISTANT DEAN, MIDWIFERY, MIDWIFE RESEARCHER/EPIDEMIOLOGIST) $^{\mathrm{FG}}$

${ }^{a}$ Department of Midwifery Science, AVAG and the EMGO Institute for Health and Care Research, VU University Medical Centre, Amsterdam, The

Netherlands

${ }^{\mathrm{b}}$ NIVEL (Netherlands Institute for Health Services Research), Utrecht, The Netherlands

${ }^{\mathrm{c}}$ The Bamford Centre for Mental Health and Wellbeing, Ulster University, Coleraine, Northern Ireland, UK

${ }^{d}$ Department of Obstetrics and Gynaecology, University of Groningen, University Medical Centre Groningen, The Netherlands

${ }^{e}$ Department of Public Health, Rural Health School, La Trobe University, Melbourne, VIC 3086, Australia

${ }^{\dagger}$ Dept. Obstetrics and Gynaecology, Faculty of Health Sciences (Midwifery), McMaster University, Hamilton, ON, Canada

${ }^{9}$ Department Midwifery Science EMGO+ VUMc, Amsterdam, The Netherlands

\section{HighLIGHTS}

- The mean rating of the postpartum care by the MCA was 8.8 (on a scale from 1 to $10)$.

- $95.6 \%$ of the women received postpartum maternity care by an MCA in their home.

- $14 \%$ of the women rated the postpartum maternity care by the MCA as 'less than good care'.

\footnotetext{
AbSTRACT

Objective: The postpartum period is an important time in the lives of new mothers, their children and their families. The aim of postpartum care is 'to detect health problems of mother and/or baby at an early stage, to encourage breastfeeding and to give families a good start' (Wiegers, 2006). The Netherlands maternity care system aims to enable every new family to receive postpartum care in their home by a maternity care assistant (MCA). In order to
} 
Baas, C.I., Wiegers, T.A., Cock, T.P. de, Erwich, J.J.H.M., Spelten, E.R., Hutton, E.K. Experiencewith and amount of postpartum maternity care: comparing women who rated the care they received from the maternity care assistant as 'good' or 'less than good care'. Midwifery: 2017, 7 55(12), 128-236

better understand this approach, in this study we focus on women who experienced the postpartum care by the MCA as 'less than good' care. Our research questions are; among postpartum women in the Netherlands, what is the uptake of MCA care and what factors are significantly associated with women's rating of care provided by the MCA. Design and setting This study uses data from the 'DELIVER study', a dynamic cohort study, which was set up to investigate the organization, accessibility and quality of primary midwifery care in the Netherlands. Participants In the DELIVER population $95.6 \%$ of the women indicated that they had received postpartum maternity care by an MCA in their home. We included the responses of 3170 women.

Measurements and findings: To assess the factors that were significantly associated with reporting 'less than good (postpartum) care' by the MCA, a full cases backward logistic regression model was built using the multilevel approach in Generalized Linear Mixed Models.

Findings: The mean rating of the postpartum care by the MCA was 8.8 (on a scale from 1-10), and 444 women (14\%) rated the postpartum maternity care by the MCA as 'less than good care'. In the full cases multivariable analysis model, odds of reporting 'less than good care' by the MCA were significantly higher for women who were younger (women 25-35 years had an OR 1.32, CI 0.961.81 and women 35 years), multiparous (OR 1.27, CI 1.01-1.60) and had a higher level of education (women with a middle level had an OR 1.84,CI 1.222.79, and women with a high level of education had an OR 2.11, CI 1.40-3.18 compared to women with a low level of education). Odds of reporting 'less than good care' were higher for women who, received the minimum amount of hours (OR 1.86, CI 1.45-2.38), in their opinion received not enough or too many hours maternity care assistance (OR 1.47, CI 1.01-2.15 and OR 5.15, CI 3.25-8.15, respectively), received care from two or more different MCAs (2 MCAs OR 1.61 CI 1.24-2.08, $\geq 3$ MCAs OR 3.01, CI 1.98-4.56 compared to 1 MCA) and rated the care of the midwife as less than good care (OR 4.03, CI 3.10-5.25) . The odds of reporting 'less than good care' were lower for women whose reason for choosing maternity care assistance was to get information and advice (OR 0.52, CI 0.41-0.65).

Key conclusions: We conclude that (the postpartum) MCA care is well utilised, and highly rated by most women. Implications for practice:The approach to care in the Netherlands addresses the needs as outlined by NICE and WHO. Although no data exists around the impact of use on maternal infant outcomes, this approach might be useful in other jurisdictions. MCA care might be improved if the hours of MCA care were tailored, and care by multiple MCAs minimised.

\section{INTRODUCTION}

The postpartum period is an important time in the lives of new mothers, their children and their families. It is a time of changes, transitions and emotions (Shaw et al., 2006). The aim of postpartum care is 'to detect health problems of mother and/or 
Baas, C.I., Wiegers, T.A., Cock, T.P. de, Erwich, J.J.H.M., Spelten, E.R., Hutton, E.K. Experiencewith and amount of postpartum maternity care: comparing women who rated the care they received from the maternity care assistant as 'good' or 'less than good care'. Midwifery: 2017, $55(12), 128-236$

baby at an early stage to encourage breastfeeding and to give families a good start' (Wiegers, 2006). Internationally, women's evaluation of postpartum care has consistently been more negative than their rating of other episodes of maternity care. Despite such evaluations postpartum care is often given low priority in research and practice (Rudman and Waldenstrom, 2007; Morrow et al., 2013) From the perspective of both postnatal women and care providers increasing concern has been expressed regarding postnatal care provision while at the same time there has been a lack of evidence to guide developments in postpartum care (Rudman and Waldenstrom, 2007; Bick et al. 2011; Morrow et al., 2013). The importance of professional postpartum care is described in the World Health Organisation and United Nations Children's Fund (WHO/UNICEF) standard as well as in the National Institute for Health and Care Excellence (NICE) guideline and the NICE quality standard (WHO/UNICEF 2009; NICE, 2013). In their joint statement

WHO/UNICEF recommend home visits by qualified care providers in the baby's first week of life based on studies showing that home-based new born care interventions can prevent 30-60\% of new born deaths in high mortality settings under controlled conditions. The NICE guideline is one of the few guidelines that covers routine postpartum care for the mother and infant (Haran et al., 2014). In high-income countries some studies have shown postpartum home visits to be effective in improving breastfeeding rates and parenting skills (Avellar and Supplee, 2013; Shaw et al., 2006). A Cochrane review (2013) concluded that, although postpartum home visits may promote infant health and maternal satisfaction, the evidence was inconsistent and that the frequency, timing, duration and intensity of postpartum care visits should be based upon local needs (Yonemoto et al., 2013).

The care provided in the postpartum period differs across jurisdictions and maternity care models, in terms of duration of postpartum hospital stay, frequency and number of home visits as well as care provider qualification (Bick et al., 2008; Schmied and Bick, 2014).

The Netherlands' maternity care system aims to enable every new family to receive postpartum care in their home (Stuurgroep zwangerschap en geboorte, 2009). In the Netherlands $13 \%$ of the women give birth at home and $87 \%$ in hospital or a birth centre following which they will usually return home within a few hours (Stichting Perinatale Registratie Nederland, 2015). At home the new family receives care from a team of a midwife and maternity care assistant (MCA). A primary care midwife will visit the family 3-5 times (or more when necessary) in the first 8-10 days after birth. The MCA provides care (3-8 hours per day) up to 8 to 10 days after birth (Wiegers, 2006). Every year nearly 170,000 women give birth in the Netherlands and an estimated $90 \%$ of those families receive postpartum maternity care assistance in their home. The MCAs also assist midwives during births at home, and increasingly in hospital and birth centres. The MCA provides the mother, her partner and child with practical care, support, instruction and guidance during and after childbirth (Teijlingen van, 1990; Wiegers, 2006). The MCA has a role in assessing and screening for complications and when a complication occurs or threatens to occur, will contact the midwife who will assess the woman and/ or child and make appropriate referrals to secondary care for a consultation or admission to hospital (Teijlingen van, 1990; Wiegers, 2006). "An MCA, unlike a midwife, will be with the family for an extended period. The advantage of this is that information and education is embedded in the daily activities and therefore more easily understood 
Baas, C.I., Wiegers, T.A., Cock, T.P. de, Erwich, J.J.H.M., Spelten, E.R., Hutton, E.K. Experiencewith and amount of postpartum maternity care: comparing women who rated the care they received from the maternity care assistant as 'good' or 'less than good care'. Midwifery: 2017, 7 55(12), 128-236

and accepted, health care and psycho-social care are indissolubly intertwined. The timely detection of symptoms that may lead to health problems later will help reduce readmissions rates and thereby reduce costs (Wiegers, 2006). Another advantage is that with the help of a MCA mothers may have more opportunity to will rest thus ameliorating tiredness and fatigue, which are described as the most common problem affecting new mothers. (Schytt et al., 2005; Badr and Zauszniewski, 2017).”A possible disadvantage is that it increases health care costs. However, the availability of maternity care assistance makes home birth and early discharge after hospital birth possible, thereby reducing health care costs. In the Netherlands the care in the postpartum period is substantially less studied compared to the care in the prenatal and intrapartum period with little research related to women's ratings of the care by MCAs. The approach to care in the Netherlands appears to address the needs as outlined by NICE and WHO, however before other health care systems could consider using an approach that would include an MCA, it is useful to evaluate more carefully the organization of and experience with postpartum care, including the care provided by the maternity care assistants, in the Netherlands. In this study, we focus on women who experienced the postpartum care by the MCA as 'less than good' care.

The purpose of this study was twofold: first, we were interested in getting a better understanding of the uptake of maternity care assistance during the postpartum period in the Netherlands; and second, we investigated which factors affected the women's rating of postpartum maternity care by the MCA. Our research questions were: (1) among postpartum women in the Netherlands what is the uptake of MCA care and (2) what factors are significantly associated with women's ratings of care provided by the MCA? To address the latter, we compared women who rated care they received by the MCA as 'good' and 'less than good care'.

\section{Postpartum care by Maternity Care Assistants (MCAs) in The Netherlands}

1. MCA education: 3 year senior secondary vocational education (without experience or previous relevant education)

2. In general, women sign up for MCA at the end of the first trimester of their pregnancy.

3. Every person in the Netherlands is statutorily insured for health care costs and MCA is included in the basic health care package that is available for everyone.

4. A co-payment of 4.15 euro per hour is required (in 2016) for postpartum maternity care assistance, for which people can take out an additional insurance.

5. The standard for postpartum maternity care assistance is 49 hours in 8 consecutive days, beginning at the day of birth. The legally defined minimum is 24 hours in up to 8 days and the maximum is 80 hours, in a period of 10 days.

6. Because MCA is care to be provided at home (or in a home-like environment), for each day spent in hospital after giving birth one eighth is deducted from the agreed upon number of hours, based on the notion that during their hospital stay they also receive postpartum care, not from an MCA, but from an obstetrical nurse. This was meant to encourage women with an uncomplicated birth to return home as soon as possible, thereby reducing the health care costs. 
Baas, C.I., Wiegers, T.A., Cock, T.P. de, Erwich, J.J.H.M., Spelten, E.R., Hutton, E.K. Experiencewith and amount of postpartum maternity care: comparing women who rated the care they received from the maternity care assistant as 'good' or 'less than good care'. Midwifery: 2017, 7 55(12), 128-236

7. The average duration of postpartum care by MCAs in our study was 38.5 hours in 2010, depending on the mother's wishes, the availability of MCAs and the duration of the hospital stay after childbirth.

\section{METHODS}

This study is part of the DELIVER study (DELIVER stands for Data EersteLIjns VERloskunde, data on primary midwifery care), which is a large prospective cohort study in the Netherlands set up to investigate the organization, accessibility and quality of primary midwifery care. Data were collected from clients and their partners, midwives and other healthcare professionals across the Netherlands, between September 2009 and April 2011. Clients from twenty midwifery practices assessed their expectations and experiences. These client data were linked to data from electronic client records kept by midwives and collected by the Netherlands Perinatal Register. Methodological details of this study have been published previously (Manniën et al., 2012). The Medical Ethics Committee of VU University Medical Centre, Amsterdam approved the study protocol of the DELIVER study.

\section{Recruitment}

Clients were recruited from 20 midwifery practices. Purposive sampling was used to select practices, using three stratification criteria: region, level of urbanization and practice type (dual or group practice). The 20 participating practices included 108 midwives and about 8200 clients per year. The primary aim of the client questionnaires was to develop a profile of a pregnant woman in the Netherlands, her background, her health, her lifestyle, her work, her use of healthcare in general and in addition to that to assess her expectations and experiences with and her rating of the maternity care. Clients were eligible to participate if they were able to understand Dutch, English, Turkish or Arabic. Midwives provided the usual care to all their clients irrespective of their participation, but they were required to inform all eligible clients individually about the study and invite them to participate. To improve the overall response, a reminder was sent to all non-responders (Manniën, 2012).

\section{Participants}

Participants of our study were low-risk women (women with uncomplicated pregnancies) within the DELIVER study population in the Netherlands. Depending on their gestational age at inclusion, women may have completed up to three questionnaires at different time points: an early prenatal questionnaire was completed before 35 weeks (on average around 20 weeks gestation), a late prenatal questionnaire between 35 weeks and birth and a postpartum questionnaire at about 6 weeks postpartum. Data from the different questionnaires were linked at the personal level. Each of the three questionnaires consisted of 70-90 questions (Manniën, 2012). Women were included in this sub study when they completed the postpartum questionnaire of the DELIVER study, and indicated that they had received postpartum maternity care assistance (see Fig. 1). The DELIVER client data were linked to midwife-led care data from the Netherlands Perinatal Register (PRN, "Landelijke Verloskundige Registratie", LVR1). Linkage was successful for 3432 $(89 \%)$ of the women included in our study. Women with and without linked data were similar with regard to maternal age, nationality, education level and socioeconomic status. 
Baas, C.I., Wiegers, T.A., Cock, T.P. de, Erwich, J.J.H.M., Spelten, E.R., Hutton, E.K. Experiencewith and amount of postpartum maternity care: comparing women who rated the care they received from the maternity care assistant as 'good' or 'less than good care'. Midwifery: 2017, 7 55(12), 128-236

\section{[FIGURE 1]}

\section{Outcome measures}

To assess the care provided by the maternity care assistant women were asked the following question: "Please rate your overall feelings about the care provided by your maternity care assistant in the days following the birth of your child on a scale from 1 to 10, with 1 indicating the worst possible care and 10 indicating the best possible care."

We dichotomized the outcome variable into "less than good" care (rating 1-7) and "good to best possible" care (rating 8-10). This division is based on the Dutch school system, where an eight or more has the meaning of a good to best possible performance and a 7 or less for a moderate to worst possible performance (EPNuffic, 2015).

\section{Independent measures}

The rating of the quality ('good' or 'less than good care') and experience with the quantity (number of hours of care) was studied and we analysed which of the variables were significantly associated with "less than good" care by the MCA. From the background characteristics (Table 1) the following characteristics were used; age (mean and in categories; $<25,25-35$ and $>35$ years old), parity (primi-and multiparae), having a partner (yes/no), nationality (Native Dutch/ Western nonDutch/ Non Western), educational level (low, middle, high educational level), social economic status (SES, 1,2,3 1 is low and 3 is high), perceived influence on own health (yes/no), depression symptoms (yes or somewhat / no) and insurance coverage (basic/ basic plus supplementary package). In addition to the socio-demographic information, data about the preparation for the intra- and postpartum maternity care by the MCA was described (Table 2). The following data were obtained from the late prenatal questionnaire: planned place of birth (at home/hospital/birth centre), intake with the MCA organisation (yes by phone or at home/not yet/no), agreed number of hours maternity care assistance, plans to breastfeed (yes/no) and plans to have an MCA present at birth.

\section{[TABLE 1][TABLE 2]}

Furthermore the actual received postpartum care was obtained from the postpartum questionnaire: was the MCA present at birth (yes/no), when did the MCA arrive (well before birth/shortly before or during birth/after birth), how long was the MCA present during the birth ( $<1$ hour, between 1 and 2 hour or $>2$ hour), did the MCA remain with the woman that day (yes/no she left after birth/I don't know), the reason for choosing postpartum maternity care assistance (help during birth/physical help postpartum/information and advice/practical help at home /other), number of days of maternity care assistance $(<6 / 6 / 7 / 8 />8$ days $)$, total hours maternity care assistance, did the woman receive the number of hours as agreed in pregnancy (yes/no, fewer hours/no, more hours/I don't know), what was the reason for not getting the hours as agreed (hospital stay after birth/twins/health issues (baby or mother)/ feeding problems/co-payment to high/ requested a change in hours/the organisation did not have sufficient staff/other), opinion about number of hours (not enough/barely enough/enough/too many hours), provided the same MCA the care during the total period (yes/yes, but only a different MCA at childbirth/no, after a few days came a different MCA/no, there were 3 or more MCA's), patient centeredness score of the 
Baas, C.I., Wiegers, T.A., Cock, T.P. de, Erwich, J.J.H.M., Spelten, E.R., Hutton, E.K. Experiencewith and amount of postpartum maternity care: comparing women who rated the care they received from the maternity care assistant as 'good' or 'less than good care'. Midwifery: 2017, 7 55(12), 128-236

MCA (median and mean), did the woman breastfeed her child (yes/partly/no/ not anymore, but I did the first days or weeks), rating of the postpartum care of the midwife and of the MCA ( rating 1-7 /8-10) and did the woman have a follow up examination (yes with midwife or gynaecologist/ I made an appointment/no). These determinants were all categorical variables except for patient centeredness scale (see Tables 1 and 2). The experienced patient-centeredness of the MCA was measured using a patient-centeredness scale in which the questions are based on quality indicators about treatment by a particular caregiver at a particular time (for example: Did your MCA listen to you carefully? Did your MCA take you seriously?). The patient centeredness scale contains 7 items measuring frequency on a four-point scale ('never'(1), 'sometimes'(2), 'usually'(3) and 'always'(4)), and has an internal consistency coefficient of 0.9 . The patient-centeredness scale was analysed using the mean score (sum score divided by 7 , yielding a continuous variable with a score ranging between 1.0 - 4.0) (NIVEL, 2017).

\section{Analyses}

First we described the background and care-specific characteristics in the study. To assess the factors that were significantly associated with the rating of the experienced maternity care assistance, first a full cases univariate analysis was performed. Thereafter a backward logistic regression model was built using the factors shown to be significant in the univariable analyses and variables that by means of reasoning could be associated with the rating of the MCA care. In steps, the variables with the highest $\mathrm{p}$-values were removed from the model, then the changes in the odds ratios and $p$-values were studied. In the final model only variables with p-values of 0.05 and below were maintained (Table 3). Because the data consisted of two levels of data, the respondents and the midwifery practices, we used the multilevel approach in Generalized Linear Mixed Models, IBM SPSS Statistics, version 21, Chicago, IL.

\section{FINDINGS}

\section{Participants}

Of all 14,418 eligible clients of the participating midwifery practices, 7685 women participated by returning at least one questionnaire (response rate 53\%). About a quarter of these women $(n=1800)$ completed all three questionnaires during the oneyear study period. From the 4146 women who completed the postpartum questionnaire, $95.6 \%$ indicated that they had received postpartum maternity care by an MCA in their home (Fig. 1). Following our other exclusion criteria for this (sub) study, 3170 women remained. Of those 3170 women, 2013 also responded to the late prenatal questionnaire and gave answers about the preparation for the postpartum period (Fig. 1). The mean age of our study sample was 31.0 years (SD 4.5), 46.1\% of the women were primipara and $53.9 \%$ multipara (Table 1). The large majority of the women was native Dutch (96\%), had a middle or high level of education $(53.1 \%$ high level, $34.8 \%$ middle level) and had a spontaneous vaginal birth (82.1\%).

\section{Analyses}

Of the 3170 women, 444 women (14\%) rated the postpartum maternity care by the MCA as 'less than good care'. The mean rating of the received postpartum care by the MCA (and the care by the midwife also) was 8.8 (on a scale from 1 to 10 , with 1 indicating the worst possible care and 10 indicating the best possible care). With regards to the prenatal preparation and/or planning (see Tables 2), 98.5\% of the 
Baas, C.I., Wiegers, T.A., Cock, T.P. de, Erwich, J.J.H.M., Spelten, E.R., Hutton, E.K. Experiencewith and amount of postpartum maternity care: comparing women who rated the care they received from the maternity care assistant as 'good' or 'less than good care'. Midwifery: 2017, 7 55(12), 128-236

women had prenatal intake (visit or phone call) with the MCA organisation to discuss the postpartum care and 59\% of the women planned for an MCA to be present at birth. Of the women who did not plan for the MCA to be present at birth, $87.8 \%$ planned to give birth in hospital.

\section{Multivariable analyses}

The 'patient centeredness of the MCA' was excluded from the multivariable model due to a very high correlation with the rating of the postpartum care by the MCA. There was no collinearity between the measures.

The full cases multivariable analysis showed the same determinants to be significant as in the univariable analyses with the exception that the adjusted OR was not significant for depression symptoms and whether the MCA was present at birth or not. In the full cases multivariable analysis model odds of reporting 'less than good care' by the MCA were significantly higher for women who were younger (women 25-35 years had an OR 1.32, CI 0.96-1.81 and women<25 years had an OR 1.90, CI 1.14-3.16) compared to women who were $>35$ years), multiparous (OR 1.27, CI 1.01-1.60) and had a higher level of education (women with a middle level had an OR 1.84, CI 1.22-2.79 and women with a high level of education had an OR 2.11, CI 1.40-3.18 compared to women with a low level of education). With regards to the care odds of reporting 'less than good care' were higher for women who received the minimal amount of hours (OR 1.86, CI 1.45-2.38), in their opinion received not enough or too much hours maternity care assistance (OR 1.47,CI 1.01-2.15 and OR 5.15, CI 3.25-8.15 respectively), received care from more different MCAs (2 MCAs OR 1.61,CI 1.24-2.08), $\geq 3$ MCAs OR 3.01, CI 1.98-4.56 compared to 1 MCA) and rated the care of the midwife as less than good care (OR 4.03, CI 3.10-5.25). The odds were lower for women whose reason for choosing maternity care assistance was to get information and advice (OR 0.52, CI 0.41-0.65).

\section{DISCUSSION}

The maternity care system in the Netherlands aims to enable every new family to receive postpartum care in their home (Stuurgroep zwangerschap en geboorte, 2009). In our study sample, $95.6 \%$ of the women indicated that they had received postpartum maternity care by an MCA in their home. Concerning the prenatal preparation for and planning of the postnatal period, $98.5 \%$ of the women had a prenatal intake (visit or phone call) with the MCA organisation to discuss the postpartum care and 59\% of the women planned for an MCA to be present at birth. From the women who did not plan for the MCA to be present at birth, $87.8 \%$ planned to give birth in hospital. It is likely that women who planned their birth in hospital assumed that, instead of the MCA, a nurse would be present, which is common in the Netherlands.

The postpartum care by the MCA was rated with a mean rating of 8.8 (on a scale from 1 to 10 , with 1 indicating the worst possible care and 10 indicating the best possible care), equal to the rating of intrapartum and postpartum midwifery care (both 8.8) and higher than the rating of prenatal midwifery care (8.4). So it can be concluded that overall women rated the postpartum care by the MCA as 'good to best possible' care. This high rating of the postpartum care in the Netherlands is not congruent with the international literature, where postpartum care is generally given a lower rating than other episodes of maternity care (Brown, 2005; Rudman and Waldenstrom 2007; Fenwick 2010; Hildingsson and Sandin-Bojo 2011; Todd et al., 
Baas, C.I., Wiegers, T.A., Cock, T.P. de, Erwich, J.J.H.M., Spelten, E.R., Hutton, E.K. Experiencewith and amount of postpartum maternity care: comparing women who rated the care they received from the maternity care assistant as 'good' or 'less than good care'. Midwifery: 2017, 7 55(12), 128-236

2017). Despite this overall high rating 444 (14\%) of women rated their postpartum care by the MCA as 'less than good care' (with a score of 7 or less). One of our first observations was that the patient-centeredness of the MCA, as reported by women, almost fully explained the rating of postpartum care by MCAs. Patient centeredness of the care provider seems to be a key factor in explaining the rating of the care. Other studies regarding health care providers report similar results (Brown et al., 2005; Hildingsson and Thomas, 2007; Jenkins et al., 2014; Todd et al., 2017). A recent study from Todd et al. (2017) demonstrated that "women who were 'always or almost always' treated with kindness and understanding were 1.8-2.8 times more likely to rate their antenatal, birth and postnatal care as 'very good' care". Regarding the characteristics of women, the odds of rating the postpartum MCA care as 'less than good' care were higher for women who were younger; were multiparous and had a higher level of education. Women who gave lower ratings for the postpartum MCA care also rated the care of the midwife as less than good care; and women gave higher ratings for the MCA care if they indicated that their reason to choose maternity care assistance was to get information and advice. Furthermore, with regard to the received care the odds of rating the postpartum MCA care as 'less than good' care were higher for women who: received the minimum amount of hours; in their opinion, received either not enough or too many hours maternity care assistance; received care from more different MCAs (less continuity).

These data suggest that continuity of MCA provider and adequate hours of care are important factors associated with evaluating care highly. However, it is possible that women who were displeased with their MCA requested a change of care provider, contributing to lack of continuity. Similarly, women who were displeased with their MCA care may have requested that the hours be reduced. Thus while we observe an association, direction and causality cannot be presumed.

There are women who assessed the postpartum care by the MCA as too much care and there are women who assess the care as not enough care. A recommendation would be that the hours of care by the MCA could be more tailored. For example, currently days in the hospital are being deducted from the hours of maternity care assistance available postpartum. Women with a lengthier postpartum hospital stay for caesarean section or other complication of birth are likely to be less mobile and more in need of care than, for example, multipara who had an uncomplicated (home) birth, yet they will receive fewer hours of MCA care at home.

Women who rated the care by the MCA as less than good care have higher odds to rate the care by the midwife as less than good care. We have no explanation for this based on our data. There could be a bias dependent on experience in the sense that the overall evaluation of the birth experience affects how women remember all the care they received.

The sample was generally representative of the Dutch population except with regard to the percentage of women with non-Dutch Nationality (Perinatal Registration Netherlands, data 2010: primip, 47.5\%, multip 52.5\%. 21.3\% non-Dutch, mean age 31.0 (SD 5.0) (Stichting Perinatale Registratie Nederland, 2010). "More than $90 \%$ of Dutch women and about $85 \%$ of non-Dutch women receive maternity care assistance. Women of foreign origin may make less use of maternity care assistance than Dutch women because they are less familiar with the service, have not been informed properly or expect help from their own family (Wiegers, 2006). 
Baas, C.I., Wiegers, T.A., Cock, T.P. de, Erwich, J.J.H.M., Spelten, E.R., Hutton, E.K. Experiencewith and amount of postpartum maternity care: comparing women who rated the care they received from the maternity care assistant as 'good' or 'less than good care'. Midwifery: 2017, 7 $55(12), 128-236$

Although Non Dutch women apply less frequently for maternity care assistance because of cultural reasons, this is not the reason of the low number of non-Dutch women in our sub study. The reason is that the main Deliver study had difficulty reaching these women. Overall only $5 \%$ non-Dutch women responded to the postpartum questionnaire. The mode of birth was not generally representative to the childbearing population in the Netherlands, but that was to be expected because this study was among women who started their care in primary care (low risk population). In our group there was a larger proportion of women with a spontaneous vaginal birth. Our recommendation for future research is to investigate the experience with postpartum maternity care by MCAs among women who started their prenatal/natal care in secondary/ tertiary care as well. A recommendation for practice is that the MCA organizations provide a clear explanation about the main tasks of the MCA and include a discussion about the expectations of the family at intake. This will assist the woman and her partner in realizing that one of the most important tasks of the MCA is to provide information and advice (and not to clean the house, for example) and in this way the postpartum care by the MCA will even better fulfil the families' expectations.

One of the strengths of our study was that we were able to collect data about a large group of women $(N=3170)$ who started their pregnancy in primary care. A weakness of our study was the low percentage of women from other nationalities. We conclude that MCA care is well utilized and highly rated by most women. Furthermore, the approach to care in the Netherlands addresses the needs as outlined by NICE and WHO. Although no data exist around the impact of use on maternal infant outcomes, this approach might be useful in other jurisdictions.

\section{FUNDING SOURCE}

This article was funded by the KNOV (the Royal Dutch Organization of Midwives); a PhD-scholarship.

\section{CONFLICT OF INTEREST}

The authors declare no conflict of interest.

\section{ACKNOWLEDGMENTS}

We would like to thank the clients, their partners and the midwives for their time and effort to participate in the DELIVER study. Furthermore, we would like to thank the KNOV (the Royal Dutch Organization of Midwives) for their PhD-scholarship.

\section{REFERENCES}

Avellar, S., A., Supplee, L., H., 2013. Effectiveness of home visiting in improving child health and reducing child maltreatment. Pediatrics 132, 90.

Badr, H., A., Zauszniewski, J., A., 2017. Meta-analysis of the predictive factors of postpartum fatigue. Applied Nursing Research 36, 122-127.

Bick, D., Bastos, M., H., Diniz, S., G., 2008. Unlocking the potentional of effective care for life-long meternal and infant health:the need to address the ínvisible'service after birth. Revista da escola de emfermagem da USP 42, 416-421.

Bick, D., Rose, V., Weavers, A., Wray, J., Beake, S., 2011. Improving inpatient postnatal services:midwives views and perspectives of engagement in a quality improvement initiative. BioMed Central Health Services Research 11, 293. 
Baas, C.I., Wiegers, T.A., Cock, T.P. de, Erwich, J.J.H.M., Spelten, E.R., Hutton, E.K. Experiencewith and amount of postpartum maternity care: comparing women who rated the care they received from the maternity care assistant as 'good' or 'less than good care'. Midwifery: 207 55(12), 128-236

Brown, S., B., Davey, M., Bruinsma, F., J., 2005. Women's views and experiences of postnatal hospital care in the Victorian survey of recent mothers 2000. Midwifery 21, 109126.

EP-Nuffic, 2015. Education system the Netherlands, The Dutch education system described, version 4. Retrieved 15/01/2017, from. Fenwick, J., Butt, J., Dhaliwal, S., Hauck, Y., Schmied, V., 2010. Western Australian women's perception of the style and quality of midwifery postnatal care in hospital and at home. Women and Birth 23, 10-21.

Haran, C., Driel van, M., Mitchell, B., L., Brodribb, W., E., 2014. Clinical guidelines for postpartum women and infants in primary care-a systematic review. Biomed Central Pregnancy and Childbirth 14, 51.

Hildingsson, I., M., Sandin-Bojo, A., 2011. 'What is could indeed be better'-Swedish women's perceptions of early postnatal care. Midwifery 27, 737-744.

Hildingsson, I.M., Thomas J, E., 2007. Women's perspectives on maternity services in Sweden: processes, problems and solutions. Journal of Midwifery and Womens Health 52 , 126-133.

Jenkins, M., G., Ford, J., B., Morris, J., M., Roberts, C., L., 2014. Women's expectations and experiences of maternity care in NSW-What women highlight as most important. Women and Birth. http://dx.doi.org/10.1016/i.wombi.2014.03.002.

Manniën, J., Klomp, T., Wiegers, T., Pereboom, M., Brug, J., de Jonge, A., van der Meijde, M., Hutton, E., Schellevis, F., Spelten, E., 2012. Evaluation of primary care midwifery in the Netherlands: design and rationale of a dynamic cohort study (DELIVER). BioMed Central Health Services Research 12, 69.

Morrow, J., McLachlan, H., Forster, D., Davey, M., Newton, M., 2013. Redesigning postnatal care: exploring the views and experiences of midwives. Midwifery 29, 159-166.

NICE, 2013. Postnatal care: NICE quality Standard 37. Retrieved 15/01/2017, from $\langle$ www.guidance.nice.org.uk/qs37〉.

NIVEL. (Netherlands institute for health services research), Primary Care Database. Retrieved 15/01/2017, from 〈https://www.nivel.nl/nl/cq-index〉.

Rudman, A., Waldenstrom, U., 2007. Critical views on postpartum care expressed by new mothers. BioMed Central Health Services Research 7, 178.

Schmied, V., Bick, D., 2014. Postnatal care- current issues and future challenges. Midwifery 30, 571-574.

Schytt, E., Lindmark, G., Waldenström, U., 2005. Physical symptoms after childbirth: prevalence and associations with self-rated health. An International Journal of Obstetrics Gynaecology 112, 210-217.

Shaw, E., Levitt, C., Wong, S., Kaczorowski, J., 2006. Systematic review of the literature on postpartum care: effectiveness of postpartum support to improve maternal parenting, mental health, quality of live, and physical health. Birth 33, 210-220.

Stichting Perinatale Registratie Nederland. Perinatale Zorg in Nederland 2010 and 2015. Utrecht: Stichting Perinatale Registratie Nederland. Retrieved 15/01/2017, from 〈https://assets.perined.nl/docs/980021f9-6364-4dc1-9147-d976d6f4af8c.pdf〉.

Stuurgroep zwangerschap en geboorte ('Steering Group Pregnancy and Childbirth'), 2009. een goed begin, Veilige zorg rondom zwangerschap en geboorte.

Teijlingen van, E., R., 1990. The profession of maternity home care assistant and its significance for the Dutch midwifery profession. International Journal of Nursing Studies 27, 355-366.

Todd, A., L., Ampt, A., J., Roberts, C., L., 2017. "Very good" ratings in a survey of maternity care: kindness and understanding matter to Australian Women. Birth 44, 48-57.

WHO / UNICEF, 2009. Joint statement. Home visits for the newborn child: a strategy to improve survival. Retrieved 15/01/2017, from 〈http://apps.who.int/iris/bitstream/10665/70002/1/WHO_FCH_CAH_09.02_eng.pdf〉.

Wiegers, T., A., 2006. Adjusting to motherhood maternity care assistance during the postpartum period: how to help new mothers cope. Journal of Neonatal Nursing 12, 163171.

Yonemoto, N., Dowswell, T., Nagai, S., Mori, R., 2013. Schedules for home visits in the early post partum period (Review). The Cochrane Collaboration. 
Baas, C.I., Wiegers, T.A., Cock, T.P. de, Erwich, J.J.H.M., Spelten, E.R., Hutton, E.K. Experiencewith and amount of postpartum maternity care: comparing women who rated the care they received from the maternity care assistant as 'good' or 'less than good care'. Midwifery: 2017, 7 55(12), 128-236

\section{FIGURES AND TABLES}

Fig. 1. Flowchart: Number (n) of participants of the 'DELIVER' study who were included in our study.

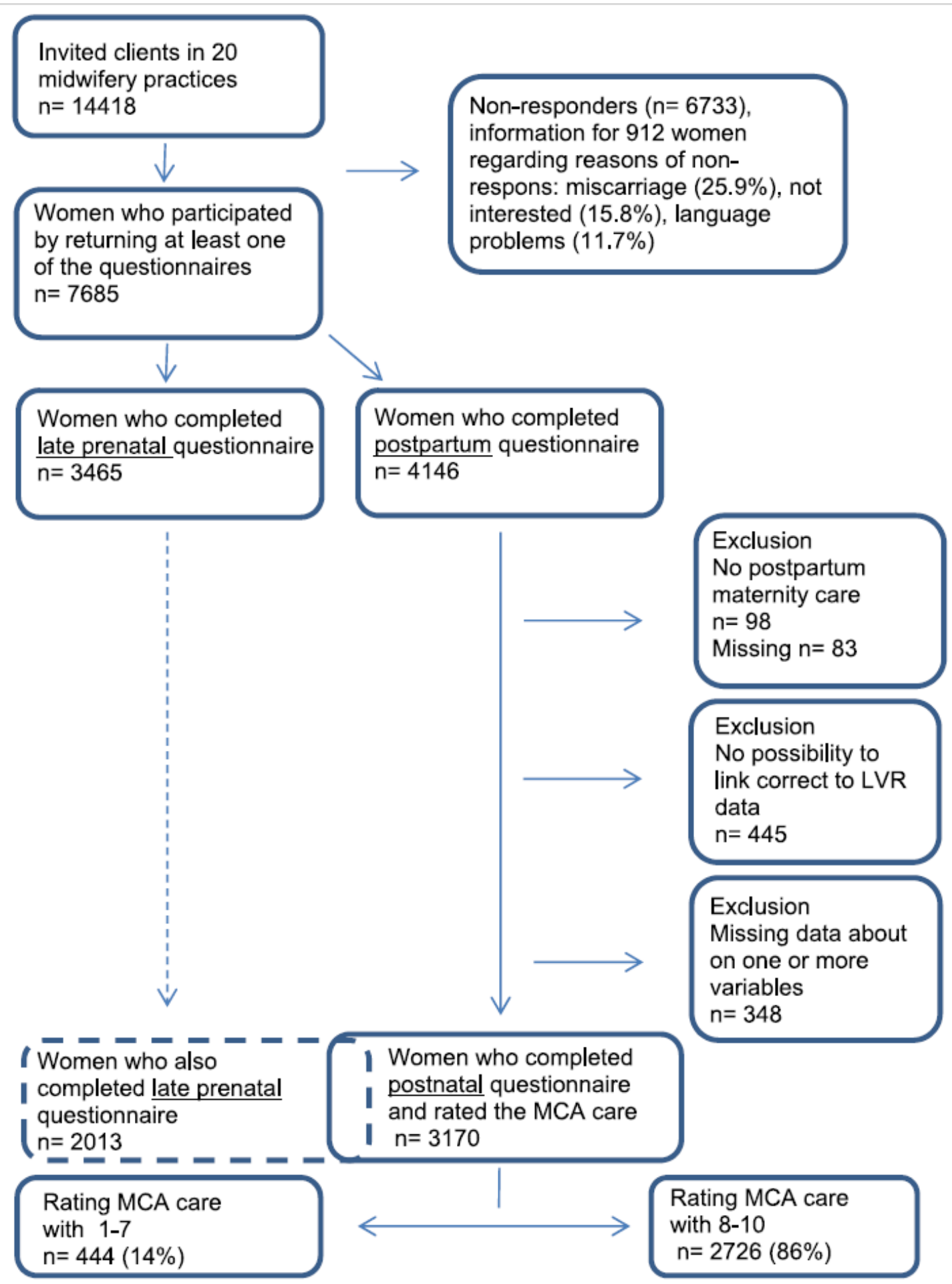


Baas, C.I., Wiegers, T.A., Cock, T.P. de, Erwich, J.J.H.M., Spelten, E.R., Hutton, E.K. Experience with and amount of postpartum maternity care: comparing women who rated the care they received from the maternity care assistant as 'good' or 'less than good care'. Midwifery: 20 55(12), 128-236

Table 1. Background characteristics participants 'Deliver' study, who responded to the postpartum questionnaire and had rated MCA postpartum care. Data collected between September 2009 and April 2011 in the Netherlands. ( $n=3170=$ full cases $)$.

\begin{tabular}{|c|c|c|c|}
\hline & \begin{tabular}{|l|} 
Total \\
$N=3170$
\end{tabular} & \begin{tabular}{|c} 
Rating MCA care 1- \\
$7 \mathrm{~N}=444(14 \%)$
\end{tabular} & $\begin{array}{l}\text { Rating MCA care } 8-10 ~ N \\
=2726(86 \%)\end{array}$ \\
\hline \multicolumn{4}{|c|}{ J } \\
\hline Mean (SD) & $31.0(4.5)$ & $30.8(4.5)$ & $31.0(4.5)$ \\
\hline (Min-max) & $(17-46)$ & $(19-43)$ & $(17-46)$ \\
\hline \multicolumn{4}{|l|}{ Parity ${ }^{x}$} \\
\hline Primiparae & $1461(46.1)$ & $197(44.4)$ & $1264(46.4)$ \\
\hline Multiparae & 1709(53.9) & $247(55.6)$ & 1462(53.6) \\
\hline \multicolumn{4}{|l|}{ Partner } \\
\hline Yes & $3129(98.7)$ & $438(98.6)$ & $2691(98.7)$ \\
\hline No & $41(1.3)$ & $6(1.4)$ & $35(1.3)$ \\
\hline \multicolumn{4}{|l|}{ Nationality } \\
\hline Native Dutch & $\begin{array}{r}3042 \\
(96.0)\end{array}$ & $418(94.1)$ & 2624(96.3) \\
\hline Western non-Dutch & $66(2.1)$ & $12(2.7)$ & $54(2.0)$ \\
\hline \begin{tabular}{|l} 
Non Western \\
\end{tabular} & $62(2.0)$ & $14(3.2)$ & $48(1.8)$ \\
\hline \multicolumn{4}{|l|}{$\mid \overline{\text { Educational level } \Delta^{*}}$} \\
\hline Low & $385(12.1)$ & $38(8.6)$ & $347(12.7)$ \\
\hline Middle & $1103(34.8)$ & $154(34.7)$ & $949(34.8)$ \\
\hline High & $1682(53.1)$ & $252(56.8)$ & $1430(52.5)$ \\
\hline \multicolumn{4}{|l|}{ Socio Economic Status } \\
\hline $1 \mathrm{High}$ & $836(26.4)$ & $121(27.2)$ & $715(26.2)$ \\
\hline 2 & $1498(47.3)$ & $184(41.1)$ & $1314(48.2)$ \\
\hline 3 Low & $836(26.4)$ & $139(31.3)$ & $697(25.6)$ \\
\hline \multicolumn{4}{|l|}{\begin{tabular}{|l|l} 
Influence own health \\
\end{tabular}} \\
\hline Yes & $2758(87.0)$ & $381(85.8)$ & $2377(87.2)$ \\
\hline No & $412(13.0)$ & $63(14.2)$ & $349(12.8)$ \\
\hline \multicolumn{4}{|l|}{$\begin{array}{l}\text { Anxious/depressed } 6 \\
\text { weeks pp }\end{array}$} \\
\hline Yes/Somewhat & $512(16.2)$ & $92(20.7)$ & $420(15.4)$ \\
\hline No & $2658(83.8)$ & $352(79.3)$ & $2306(84.6)$ \\
\hline \multicolumn{4}{|l|}{ "Health insurance } \\
\hline $\begin{array}{l}\text { Basic health insurance } \\
\text { package }\end{array}$ & $381(12.0)$ & 60 (13.5) & $321(11.8)$ \\
\hline \begin{tabular}{|l|} 
Basic package plus \\
supplementary
\end{tabular} & $2789(88.0)$ & $384(86.5)$ & $2405(88.2)$ \\
\hline \multicolumn{4}{|l|}{ Mode of birth } \\
\hline Spontaneous birth & $2604(82.1)$ & $359(80.9)$ & $2245(82.4)$ \\
\hline Instrumental birth & $333(10.5)$ & $47(10.6)$ & $286(10.5)$ \\
\hline Caesarean & $233(7.4)$ & $38(8.6)$ & 195(7.2) \\
\hline \multicolumn{4}{|l|}{$\begin{array}{l}\text { Rating midwifery } \\
\text { intrapartum care }\end{array}$} \\
\hline Mean score (SD) & $8.8(1.3)$ & $8.4(1.5)$ & $8.9(1.2)$ \\
\hline Missing & 42 & 4 & 38 \\
\hline
\end{tabular}


Baas, C.I., Wiegers, T.A., Cock, T.P. de, Erwich, J.J.H.M., Spelten, E.R., Hutton, E.K. Experiencewith and amount of postpartum maternity care: comparing women who rated the care they received from the maternity care assistant as 'good' or 'less than good care'. Midwifery: 2017, 55(12), 128-236

$\Delta$ Educational level: Low= primary school/ preparatory secondary vocational education/general secondary education Middle= senior secondary vocational education/ senior general secondary education/ pre-university education High = bachelor, master degree or post-graduate degree

* Significant, $p \leq 0.05$.

Table 2. Client related characteristic of participants who responded to late prenatal and postpartum questionnaire and had rated MCA postpartum care. Preparation in pregnancy for, and women's rating of, intrapartum and postpartum maternity care assistance by MCA's.

\begin{tabular}{|c|c|c|c|}
\hline & Total & \begin{tabular}{|c} 
Rating MCA \\
care 1-7
\end{tabular} & \begin{tabular}{|c|} 
Rating MCA \\
care $8-10$ \\
\end{tabular} \\
\hline Planning /preparations prenatal & $\begin{array}{c}N=2013 \\
(\%)\end{array}$ & $N=283(14 \%)$ & $N=1730(86 \%)$ \\
\hline \multicolumn{4}{|l|}{ Planned place of birth } \\
\hline At home & $948(48.1)$ & 134(48.0) & $841(48.1)$ \\
\hline Hospital (own midwife) & $655(33.2)$ & $91(32.6)$ & $564(33.4)$ \\
\hline Hospital (unknown care provider) & $287(14.6)$ & $45(16.1)$ & 242(14.3) \\
\hline At a birth centre & $6(0.3)$ & $1(0.4)$ & $5(0.3)$ \\
\hline Other. & $39(2.0)$ & $3(1.1)$ & $36(2.1)$ \\
\hline I don't know & $35(1.8)$ & $5(1.8)$ & $30(1.8)$ \\
\hline Missing & 43 & 4 & 39 \\
\hline \multicolumn{4}{|l|}{ Intake MCA ${ }^{\dagger}$ organisation } \\
\hline Yes, by phone & $746(38.3)$ & $117(42.5)$ & $629(37.6)$ \\
\hline Yes, at home & $1171(60.2)$ & 154(56.0) & $1017(60.9)$ \\
\hline Not yet & $24(1.2)$ & $3(1.1)$ & $21(1.3)$ \\
\hline No & $5(0.3)$ & $1(0.4)$ & $4(0.2)$ \\
\hline Missing & 67 & 8 & 59 \\
\hline \multicolumn{4}{|l|}{ Agreed hours (total over eight days) } \\
\hline Mean (SD) & $49(9.6)$ & $49(12.7)$ & $49(9.08)$ \\
\hline \multicolumn{4}{|l|}{ Planning to breastfeed } \\
\hline Yes & $1662(84.3)$ & $243(87.1)$ & $1419(83.9)$ \\
\hline No & $267(13.5)$ & $29(10.4)$ & 238(14.1) \\
\hline I don't know & $42(2.1)$ & $7(2.5)$ & $35(2.1)$ \\
\hline Missing & 42 & 4 & 38 \\
\hline \multicolumn{4}{|l|}{ Planning that MCA present at birth } \\
\hline Yes & $1124(58.6)$ & $151(55.7)$ & $973(59.1)$ \\
\hline No & 793(41.4) & $120(44.3)$ & $673(40.9)$ \\
\hline Missing & 96 & 12 & 84 \\
\hline \multicolumn{4}{|l|}{ Rating prenatal care midwife } \\
\hline Mean score (SD) & $8.4(0.9)$ & $8.2(0.9)$ & $8.5(0.9)$ \\
\hline Intra and postpartum care & $\mathrm{N}=3170(\%)$ & $\mathrm{N}=444(14 \%)$ & $\mathrm{N}=2726(86 \%)$ \\
\hline \multicolumn{4}{|l|}{ Was MCA present at birth $^{\times}$} \\
\hline Yes & $942(29.7)$ & $115(25.9)$ & $827(30.3)$ \\
\hline No & $2228(70.3)$ & $329(74.1)$ & $1899(69.7)$ \\
\hline \multicolumn{4}{|l|}{ When did MCA arrive $(n=939)$} \\
\hline Well before birth & $470(50.1)$ & $46(40.7)$ & $424(51.3)$ \\
\hline Shortly before or during birth & $399(42.5)$ & $57(50.4)$ & $342(41.4)$ \\
\hline
\end{tabular}


Baas, C.I., Wiegers, T.A., Cock, T.P. de, Erwich, J.J.H.M., Spelten, E.R., Hutton, E.K. Experiencewith and amount of postpartum maternity care: comparing women who rated the care they received from the maternity care assistant as 'good' or 'less than good care'. Midwifery: 20 55(12), 128-236

\begin{tabular}{|c|c|c|c|}
\hline & Total & \begin{tabular}{|l} 
Rating MCA \\
care $1-7$
\end{tabular} & $\begin{array}{c}\text { Rating MCA } \\
\text { care } 8-10\end{array}$ \\
\hline Planning /preparations prenatal & $\begin{array}{l}N=2013 \\
(\%)\end{array}$ & $N=283(14 \%)$ & $N=1730(86 \%)$ \\
\hline After the birth & $70(7.5)$ & $10(8.8)$ & $60(7.3)$ \\
\hline Missing & 3 & 2 & 1 \\
\hline \multicolumn{4}{|l|}{$\begin{array}{l}\text { How long was MCA present at birth }(n= \\
\text { 942) }\end{array}$} \\
\hline$<1$ hour & $305(32.6)$ & $32(27.8)$ & 273(33.3) \\
\hline Between 1 and 2 hour & $240(25.6)$ & $38(33.0)$ & 202(24.6) \\
\hline$>2$ hour & $391(41.8)$ & $45(39.1)$ & $346(42.1)$ \\
\hline Missing & 6 & 0 & 6 \\
\hline \multicolumn{4}{|l|}{$\begin{array}{l}\text { Did MCA remain with you after birth }(n= \\
967)\end{array}$} \\
\hline Yes & $559(59.8)$ & $55(47.85)$ & $504(61.5)$ \\
\hline No, she left & $356(38.1)$ & $55(48.85)$ & $301(36.7)$ \\
\hline I don't know & $20(2.1)$ & $5(4.3)$ & $15(1.8)$ \\
\hline Missing & 6 & 0 & 6 \\
\hline \multicolumn{4}{|l|}{ Reason for choosing in home MCA } \\
\hline 1.Help during the birth process & $852(26.9)$ & $93(20.9)$ & $759(27.8)$ \\
\hline 2.Physical help postpartum & $3078(97.1)$ & $414(93.2)$ & $2664(97.7)$ \\
\hline 3.Information and advice postpartum & $2150(67.8)$ & $224(50.5)$ & 1926(70.7) \\
\hline 4.Practical help at home postpartum & $2911(91.8)$ & $374(84.2)$ & $2537(93.1)$ \\
\hline 5.Other & $75(2.4)$ & 14(3.2) & $61(2.2)$ \\
\hline \multicolumn{4}{|l|}{ Days MCA } \\
\hline$<6$ days & $414(13.1)$ & $84(18.9)$ & $330(12.1)$ \\
\hline 6 & $377(8.7)$ & $50(11.3)$ & $227(8.3)$ \\
\hline 7 & $1000(31.5)$ & $124(27.9)$ & $876(32.1)$ \\
\hline 8 & 1124(35.5) & 142(32.0) & $982(36.0)$ \\
\hline$>8$ & $355(11.2)$ & $44(9.9)$ & $311(11.4)$ \\
\hline \multicolumn{4}{|l|}{ Total Hours MCA } \\
\hline Mean ( SD) & $38.5(14.2)$ & $33.7(15.2)$ & 39.3(13.8) \\
\hline \begin{tabular}{|l|} 
median \\
\end{tabular} & 42.0 & 36.0 & 42.0 \\
\hline \multicolumn{4}{|l|}{ Hours MCA as agreed } \\
\hline Yes & 1952(61.6) & $240(54.1)$ & $1712(62.8)$ \\
\hline Fewer hours & $501(15.8)$ & $110(24.8)$ & $391(14.3)$ \\
\hline More hours & $682(21.5)$ & $84(18.9)$ & $598(21.9)$ \\
\hline I don't know & $35(1.1)$ & $10(2.3)$ & $25(0.9)$ \\
\hline \multicolumn{4}{|c|}{\begin{tabular}{|l|l|} 
What is the reason you did not get hours & \\
as agreed $(n=1181)$
\end{tabular}} \\
\hline Hospital stay after birth & $478(40.5)$ & $74(38.3)$ & 404(40.9) \\
\hline Twins & $6(0.5)$ & $0(0.0)$ & $6(0.6)$ \\
\hline Health issues (baby) & $132(11.2)$ & $28(14.5)$ & $104(10.5)$ \\
\hline Health issues (mother) & $366(31.0)$ & $53(27.5)$ & $313(31.7)$ \\
\hline Feeding problems & $282(23.9)$ & $28(14.5)$ & $254(25.7)$ \\
\hline Co-payment too high & $3(0.3)$ & $1(0.5)$ & $2(0.2)$ \\
\hline Requested a change in hours & $145(12.3)$ & $36(18.7)$ & 109(11.0) \\
\hline Not have sufficient staff & $89(7.5)$ & $22(11.4)$ & $67(6.8)$ \\
\hline Other & $221(18.7)$ & $40(20.7)$ & $181(18.3)$ \\
\hline
\end{tabular}


Baas, C.I., Wiegers, T.A., Cock, T.P. de, Erwich, J.J.H.M., Spelten, E.R., Hutton, E.K. Experiencewith and amount of postpartum maternity care: comparing women who rated the care they received from the maternity care assistant as 'good' or 'less than good care'. Midwifery: 2017, 7 $55(12), 128-236$

\begin{tabular}{|c|c|c|c|}
\hline & Total & \begin{tabular}{|c|} 
Rating MCA \\
care $1-7$ \\
\end{tabular} & $\begin{array}{c}\text { Rating MCA } \\
\text { care } 8-10 \\
\end{array}$ \\
\hline Planning /preparations prenatal & $\begin{array}{l}N=2013 \\
(\%)\end{array}$ & $N=283(14 \%)$ & $N=1730(86 \%)$ \\
\hline \multicolumn{4}{|l|}{ Opinion about number of hours } \\
\hline Not enough hours received & $225(7.1)$ & $48(10.8)$ & $177(6.5)$ \\
\hline Barely enough hours & $924(29.1)$ & $120(27.0)$ & $804(29.5)$ \\
\hline Enough hours & 1924(60.7) & $229(51.6)$ & 1695(62.2) \\
\hline Too many hours & $97(3.1)$ & $47(10.6)$ & $50(1.8)$ \\
\hline \multicolumn{4}{|l|}{ Same MCA } \\
\hline Yes & 2044(64.5) & $237(53.4)$ & $1807(66.3)$ \\
\hline Yes, only different MCA at childbirth & $294(9.3)$ & $35(7.9)$ & $259(9.5)$ \\
\hline No, after a few days different MCA & $693(21.9)$ & $124(27.9)$ & $569(20.9)$ \\
\hline No, 3 or more MCAs & $139(4.4)$ & $48(10.8)$ & $91(3.3)$ \\
\hline \multicolumn{4}{|l|}{ Patient Centeredness MCA } \\
\hline Median (min-max) & $\begin{array}{l}4.0(1.4- \\
4.0)\end{array}$ & $3.3(1.4-4.0)$ & $4.0(2.4-4.0)$ \\
\hline Mean (SD) & $3.8(0.36)$ & $3.2(0.5)$ & $3.9(0.2)$ \\
\hline Missing & 19 & 8 & 11 \\
\hline \multicolumn{4}{|l|}{ Breastfeeding at this moment } \\
\hline Yes & $1718(54.2)$ & $247(55.6)$ & $1471(54.0)$ \\
\hline Partly & $275(8.7)$ & $42(9.5)$ & $233(8.5)$ \\
\hline No & $524(16.5)$ & $60(13.5)$ & $464(17.0)$ \\
\hline $\begin{array}{l}\text { Not anymore, but I did the first days/ } \\
\text { weeks }\end{array}$ & $653(20.6)$ & $95(21.4)$. & $558(20.5)$ \\
\hline \multicolumn{4}{|l|}{ Rating postpartum care midwife } \\
\hline $1-7$ & $418(12.2)$ & $131(29.5)$ & $246(9.0)$ \\
\hline $8-10$ & $3014(87.8)$ & $313(70.5)$ & $2480(91.0)$ \\
\hline Mean score(SD) & $8.8(1.3)$ & $8.4(1.5)$ & $8.9(1.2)$ \\
\hline \multicolumn{4}{|c|}{$\begin{array}{l}\text { Follow up examination with your midwife } \\
\text { or gynaecologist? }\end{array}$} \\
\hline Yes, with my midwife & $908(28.7)$ & $131(29.5)$ & $777(28.5)$ \\
\hline Yes, with my gynaecologist & $310(9.8)$ & $53(11.9)$ & $257(9.4)$ \\
\hline I made an appointment & $1090(34.4)$ & $137(30.9)$ & 953(35.0) \\
\hline No & $860(27.1)$ & $123(27.7)$ & $737(27.1)$ \\
\hline Missing & 2 & 0 & 2 \\
\hline
\end{tabular}

*Significant, $p \leq 0.05$.

†MCA = Maternity Care Assistant.

Table 3. Client related factors associated with a 'less than good' rating of care by the MCA postpartum. Fixed effects, multivariable logistic regression analysis using generalized estimation equations (GEE), forward procedure, full cases analysis.

\begin{tabular}{|c|c|c|c|c|c|c|}
\hline \multirow{2}{*}{\begin{tabular}{|l} 
Determinant \\
Age
\end{tabular}} & \multirow{2}{*}{\multicolumn{2}{|c|}{\begin{tabular}{|l|} 
Crude OR $(95 \% \mathrm{Cl})$ \\
Ref. $^{\dagger}$ rating MCA care \\
with 1-7
\end{tabular}}} & \multirow[t]{2}{*}{$\mathrm{p}$} & \multirow{2}{*}{\multicolumn{2}{|c|}{$\begin{array}{l}\text { Adjusted OR }(95 \% \mathrm{Cl}) \\
\text { Ref. }{ }^{\dagger} \text { rating MCA care } \\
\text { with 1-7 }\end{array}$}} & \multirow[t]{2}{*}{ p } \\
\hline & & & & & & \\
\hline$<25$ & 1.73 & $(1.11-2.70)$ & .015 & 1.90 & $(1.14-3.16)$ & .014 \\
\hline 25-35 & 1.22 & $(0.91-1.60)$ & .060 & 1.32 & $(0.96-1.82)$ & .096 \\
\hline Ref. $_{*}>35$ & & & & & & \\
\hline
\end{tabular}


Baas, C.I., Wiegers, T.A., Cock, T.P. de, Erwich, J.J.H.M., Spelten, E.R., Hutton, E.K. Experiencewith and amount of postpartum maternity care: comparing women who rated the care they received from the maternity care assistant as 'good' or 'less than good care'. Midwifery: 2077,7 $55(12), 128-236$

\begin{tabular}{|c|c|c|c|c|c|c|}
\hline \multirow{3}{*}{\begin{tabular}{|l|} 
Determinant \\
Parity \\
\end{tabular}} & \multirow{2}{*}{\multicolumn{2}{|c|}{\begin{tabular}{|l|} 
Crude OR $(95 \% \mathrm{Cl})$ \\
$\begin{array}{l}\text { Ref. } \\
{ }^{\dagger} \text { rating MCA care } \\
\text { with 1-7 }\end{array}$ \\
\end{tabular}}} & \multirow{3}{*}{$\mathrm{p}$} & \multirow{2}{*}{\multicolumn{2}{|c|}{\begin{tabular}{|l|} 
Adjusted OR (95\%Cl) \\
$\begin{array}{l}\text { Ref. } \\
{ }^{\dagger} \text { rating MCA care } \\
\text { with 1-7 }\end{array}$ \\
\end{tabular}}} & \multirow[t]{3}{*}{$p$} \\
\hline & & & & & & \\
\hline & & & & & & \\
\hline Multiparae & 1.12 & $(0.91-1.37)$ & .283 & 1.27 & $(1.01-1.60)$ & .045 \\
\hline \multicolumn{7}{|l|}{ Ref. Primiparae } \\
\hline \multicolumn{7}{|l|}{ Partner } \\
\hline No & 0.94 & $(0.39-2.26)$ & .888 & & & \\
\hline \multicolumn{7}{|l|}{ Ref. Yes } \\
\hline \multicolumn{7}{|l|}{ Nationality } \\
\hline Non Western & 1.38 & $(0.74-2.59)$ & .310 & & & \\
\hline Western non-Dutch & 1.28 & $(0.68-2.43)$ & .445 & & & \\
\hline \multicolumn{7}{|l|}{ Ref. Native Dutch } \\
\hline \multicolumn{7}{|l|}{ Educational level } \\
\hline High & 1.58 & $(1.09-2.27)$ & .015 & 2.11 & $(1.40-3.18)$ & $<.001$ \\
\hline Middle & 1.54 & $(1.05-2.25)$ & .026 & 1.84 & $(1.22-2.79)$ & .004 \\
\hline \multicolumn{7}{|l|}{ Ref. Low } \\
\hline \multicolumn{7}{|l|}{ SES } \\
\hline 3 & 1.14 & $(0.84-1.55)$ & .404 & & & \\
\hline 2 & 0.87 & $(0.66-1.13)$ & .290 & & & \\
\hline \multicolumn{7}{|l|}{ Ref 1} \\
\hline \multicolumn{7}{|l|}{ Depression symptoms } \\
\hline Yes/Somewhat & 1.41 & $(1.09-1.81)$ & .008 & & & \\
\hline \multicolumn{7}{|l|}{ Ref. No } \\
\hline \multicolumn{7}{|l|}{ Mode of Birth } \\
\hline Sc & 1.19 & $(0.82-1.72)$ & .361 & & & \\
\hline Instrumental birth & 1.02 & $(0.73-1.42)$ & .912 & & & \\
\hline \multicolumn{7}{|l|}{\begin{tabular}{|l|} 
Ref. Spontaneous birth \\
\end{tabular}} \\
\hline \multicolumn{7}{|l|}{ MCA present at birth } \\
\hline No & 1.20 & $(0.95-1.51)$ & .119 & & & \\
\hline \multicolumn{7}{|l|}{ Ref. Yes } \\
\hline \multicolumn{7}{|l|}{$\begin{array}{l}\text { Reason MCA (more answer } \\
\text { options possible) }\end{array}$} \\
\hline 1.Help during the birth process & 0.72 & $(0.56-0.92)$ & .010 & & & \\
\hline 2.Physical help postpartum & 0.34 & $(0.21-0.53)$ & $<.001$ & & & \\
\hline $\begin{array}{l}\text { 3. Information and advice } \\
\text { postpartum }\end{array}$ & 0.43 & $(0.35-0.52)$ & $<.001$ & 0.52 & $(0.41-0.65)$ & $<.001$ \\
\hline $\begin{array}{l}\text { 4.Practical help at home } \\
\text { postpartum }\end{array}$ & 0.43 & $(0.32-0.59)$ & $<.001$ & & & \\
\hline 5.Other & 1.46 & $(0.81-2.65)$ & .209 & & & \\
\hline \multicolumn{7}{|l|}{$\begin{array}{l}\text { Days postpartum maternity } \\
\text { care by MCA }\end{array}$} \\
\hline$<6$ & 1.66 & $(1.22-2.24)$ & .001 & & & \\
\hline 6 & 1.52 & $(1.06-2.17)$ & .022 & & & \\
\hline 7 & 0.96 & $(0.74-1.25)$ & .772 & & & \\
\hline$>8$ & 0.97 & $(0.68-1.40)$ & .877 & & & \\
\hline \multicolumn{7}{|l|}{ Ref. 8 days } \\
\hline Total Hours MCA & & & & & & \\
\hline Minimal amount $=3 \mathrm{hr} / \mathrm{day}$ & 2.57 & $(2.06-3.20)$ & $<.001$ & 1.86 & $(1.45-2.38)$ & $<.001$ \\
\hline Ref. Standard amount $6 \mathrm{hr} /$ day & & & & & & \\
\hline
\end{tabular}


Baas, C.I., Wiegers, T.A., Cock, T.P. de, Erwich, J.J.H.M., Spelten, E.R., Hutton, E.K. Experience with and amount of postpartum maternity care: comparing women who rated the care they received from the maternity care assistant as 'good' or 'less than good care'. Midwifery: 207 55(12), 128-236

\begin{tabular}{|c|c|c|c|c|c|c|}
\hline \multirow{3}{*}{\begin{tabular}{|l} 
Determinant \\
Hours MCA as agreed \\
\end{tabular}} & \multirow{2}{*}{\multicolumn{2}{|c|}{\begin{tabular}{|l|} 
Crude OR $(95 \% \mathrm{Cl})$ \\
Ref. ${ }^{\dagger}$ rating MCA care \\
with 1-7 \\
\end{tabular}}} & \multirow[t]{3}{*}{$\mathrm{p}$} & \multirow{2}{*}{\multicolumn{2}{|c|}{\begin{tabular}{|l|} 
Adjusted OR (95\%Cl) \\
$\begin{array}{l}\text { Ref. }{ }^{\dagger} \text { rating MCA care } \\
\text { with 1-7 }\end{array}$ \\
\end{tabular}}} & \\
\hline & & & & & & \\
\hline & & & & & & \\
\hline More hours & 1.00 & $(0.76-1.30)$ & .987 & 1.12 & $(0.84-1.49)$ & .452 \\
\hline Fewer hours & 1.89 & $(1.46-2.43)$ & $<.001$ & 1.49 & $(1.12-1.98)$ & .006 \\
\hline I don't know & 2.87 & $(1.35-6.08)$ & .006 & 2.21 & $(0.96-5.08)$ & .062 \\
\hline \multicolumn{7}{|l|}{ Ref. Yes } \\
\hline \multicolumn{7}{|l|}{ Opinion about hours MCA } \\
\hline Too many hours & 6.57 & $(4.29-10.06)$ & $<.001$ & 5.15 & $(3.25-8.25)$ & $<.001$ \\
\hline Barely enough & 1.11 & $(0.88-1.41)$ & .388 & 1.04 & $(0.81-1.34)$ & .746 \\
\hline \begin{tabular}{|l|} 
Not enough \\
\end{tabular} & 1.98 & $(1.40-2.81)$ & $<.001$ & 1.47 & $(1.01-2.15)$ & .047 \\
\hline \multicolumn{7}{|l|}{ Ref. Enough } \\
\hline \multicolumn{7}{|l|}{ Same MCA } \\
\hline No, 3 or more & 3.77 & $(2.58-5.51)$ & $<.001$ & 3.01 & $(1.98-4.56)$ & $<.001$ \\
\hline No, after few days different & 1.58 & $(1.24-2.01)$ & $<.001$ & 1.61 & $(1.24-2.08)$ & $<.001$ \\
\hline $\begin{array}{l}\text { Yes, only different than } \\
\text { childbirth }\end{array}$ & 1.00 & $(0.68-1.46)$ & .995 & 1.23 & $(0.83-1.84)$ & .303 \\
\hline \multicolumn{7}{|l|}{ Ref. Yes } \\
\hline \multicolumn{7}{|l|}{ Breastfeeding } \\
\hline No & 0.81 & $(0.60-1.10)$ & .174 & & & \\
\hline No, but made a start & 1.06 & $(0.82-1.37)$ & .679 & & & \\
\hline Partly & 1.05 & $(0.73-1.50)$ & .797 & & & \\
\hline \multicolumn{7}{|l|}{ Ref. Yes } \\
\hline \multicolumn{7}{|c|}{ Rating postpartum care midwife } \\
\hline $1-7$ & 4.27 & $(3.33-5.46)$ & $<.001$ & 4.03 & $(3.10-5.25)$ & $<.001$ \\
\hline \multicolumn{7}{|l|}{\begin{tabular}{|l|} 
Ref. 8-10 \\
\end{tabular}} \\
\hline Patient Centeredness MCA & & & $<.001$ & & & \\
\hline Composite score & 0.01 & $(0.01-0.02)$ & & & & \\
\hline
\end{tabular}

† Reference category. 